2 Williams JM, Ungerleider RM, Lofland GK, Cox JL. Left atrial isolation: new technique for the treatment of supraventricular arrhythmias. F Thorac Cardiovasc Surg 1980; 80:373-80.

3 Sonnenblick EH, Braunwald E, Williams JF $\mathrm{Jr}$, et al. Effects of exercise on myocardial force-velocity relations in intact unanesthetized man: relative roles of changes in heart rate, sympathetic activity, and ventricular dimensions. $¥$ Clin Invest 1965;44:2051.

4 Atwood JE. Exercise hemodynamics of atrial fibrillation. In: Falk RH, Podrid PJ, eds. Atrial fibrillation, mechanisms and management. New York: Raven Press, 1992; ment. $145-63$.

5 Hayes DL. Pacemaker complications. In: Furman S, Hayes DL, Holmes DR Jr, eds. A practice of cardiac pacing. Mount Kisco, New York: Futura, 1986;253-71.

6 Scheinman MM, Evans-Bell T. Catheter ablation of the atrionventricular junction: a report of the percutaneous mapping and ablation registry. Circulation 1984;70: 1024-9.

7 Cox JL, Boneau JP, Schuessler RB, Ferguson TB Jr, Cain ME, et al. Successful surgical treatment of atrial fibrillation. $\mathcal{f} \mathrm{Am}$ Med Ass 1991;266:1976-1980.

8 Guiraudon GM. Surgical treatment of atrial fibrillation. Herz 1993;18:51-9.

\section{Neurostimulation and myocardial \\ ischaemia}

SIR,-I read with interest the recent report by de Jongste et al and the editorial by Mulcahy et al on neurostimulation and the treatment of intractable angina. ${ }^{12}$ de Jongste et al provide further evidence that neurostimulation does not simply abolish chest pain but also affects myocardial ischaemia, reducing the frequency and duration of transient ischaemic episodes during ambulatory monitoring. ${ }^{1}$ They propose that the anti-ischaemic action of spinal cord stimulation may be the result of an increased oxygen supply to the heart caused by a redistribution of coronary blood flow.

I and coworkers showed that transcutaneous electric nerve stimulation (TENS) can increase resting coronary blood flow. ${ }^{3}$ We studied the effect of TENS in 34 patients with syndrome X (group 1), 15 patients with coronary artery disease (group 2 ), and 16 heart transplant recipients (group 3). Coronary blood flow velocity (CBFV) (mean (SD)) in the left coronary system was measured with a JudkinsDoppler catheter at rest and after stimulation. There was a significant increase in the resting CBFV in group 1 (from 6.8 $(4.1)$ to $10.5(5.7) \mathrm{cm} / \mathrm{s}, \mathrm{P}<0.001)$ and group 2 (from $6.8(4 \cdot 1)$ to $10.5(5 \cdot 7) \mathrm{cm} / \mathrm{s}$, $\mathrm{P}<0.001)$. However, there was no significant change in the resting $\mathrm{CBFV}$ in group 3. There were no significant changes in the coronary arterial diameters as a result of neurostimulation, suggesting that the mechanism of action of TENS is at the microcirculatory level. This is the first study to show that neurostimulation can increase coronary blood flow. This may explain its antiischaemic effects, which have been reported by several studies. ${ }^{145}$

I agree with the conclusion of Mulcahy et al that TENS and spinal cord stimulation are effective in the treatment of intractable angina and should be considered before the patient is subjected to a less tried treatment. ${ }^{2}$ Certainly, TENS treatment may provide a useful, non-invasive, and a safe alternative in the treatment of patients with intractable angina. Indeed, it may also provide a means of selecting patients who are more likely to benefit from spinal cord stimulation, a more invasive method of pain relief.

ANOOP CHAUHAN Department of Cardiology,
Royal Infirmary of Edinburgh, Lauriston Place, Lauriston Place,
Edinburgh EH3 $9 \mathrm{YW}$

1 de Jongste MJL, Haaksma J, Hautvast RWM, Hillege HL, Meyler PWJ, Staal MJ, et al. Effects of spinal cord stimulation on myocardial ischaemia during daily life in patients with severe coronary artery disease: patients with severe coronary artery disease: a prospective ambulatory electrocardio-

2 Mulcahy D, Knight C, Stables R, Fox K Lasers, burns, cuts, tingles and pumps: a consideration of alternative treatments for intractable angina. $B r$ Heart $f$ 1994;71: 406-7.

3 Chauhan A, Mullins PA, Thuraisingham SI, Taylor G, Petch MC, Schofield PM. Effects of transcutaneous electrical nerve stimulation on coronary blood flow. Circulation 1994;89:694-702.

4 Mannheimer C, Carlsson CA, Emanuelsson H, Vedin A, Waagstein F, Wilhelmsson C. The effects of transcutaneous nerve stimulaThe effects of transcutaneous nerve stimula-
tion in patients with severe angina pectoris. tion in patients with severe
Circulation 1985;71:308-16.

5 Mannheimer C, Eliasson T, Andersson B, Bergh C-H, Augustinsson LE, Emanuelsson $\mathrm{H}$, et al. Effects of spinal cord stimulation in angina pectoris induced by pacing and possible mechanisms of action. BMF 1993; 307: 477-80.

This letter was shown to the author, who replies as follows:

SIR,-Several non-randomised clinical studies showed that, in addition to its analgesic effect, neurostimulation reduced myocardial ischaemia assessed by electrocardiography during exercise testing. We confirmed these findings in a randomised study. ${ }^{1}$ Though myocardial ischaemia, when present, does not seem to be concealed by the neurostimulation, a placebo effect is likely to some extent. However, only a prospective mortality study can establish definitively that the treatment is safe. Furthermore, the mechanism for the anti-ischaemic action is not clear. Chauhan and coworkers provide us with valuable evidence of an increase in resting coronary blood flow velocity only after 5 minutes of neurostimulation. ${ }^{2}$ Their finding accords with the study by de Landsheere et $a l,{ }^{3}$ who used positron emission tomography (PET) during epidural spinal cord stimulation, and Mannheimers' recent article on the beneficial influence of spinal cord stimulation on impaired left ventricular function. ${ }^{4} \mathrm{De}$ Landsheere et al found that ST segment depression was significantly reduced during neurostimulation and that regional myocardial blood flow was increased at rest. However, they did not see a significant increase in myocardial blood flow during exercise. This latter finding may relate to the method or to a long-lasting carry over effect of neurostimulation. We showed, however, in our PET study after dipyridamole stress testing in nine patients, that the perfusion ratio in the ischaemic region increased more than the ratio in the non-ischaemic region. This indicates a redistribution phenomenon. ${ }^{5}$ Whether the presumed anti-ischaemic effect of neuro- stimulation is related to alterations in myocardial oxygen supply or in demand is not yet known.

Because neurostimulation is thought to trigger many interactions of neurohumoral compounds involved in neuronal networks, molecular biology may help us to determine the mechanism of action of neurostimulation.

Finally, before neurostimulation becomes generally accepted as an additional treatment for patients with severe angina, many technical problems remain to be overcome, such as lead dislocations and optimal stimulation characteristics, and strategies are needed to establish which patients need what kind of stimulation.

$$
\begin{array}{r}
\text { MIKE J L DE JONGSTE } \\
\text { Department of Cardiology, Thoraxcenter, } \\
\text { University Hospital of Groningen, } \\
\text { The Netherlands }
\end{array}
$$

1 De Jongste MJL, Hautvast RWM, Hillege $\mathrm{HL}$, Lie KI. Efficacy of spinal cord stimulation as adjuvant therapy for intractable angina pectoris: a prospective randomized clinical study. F Am Coll Cardiol 1994; clinical study

2 Chauhan A, Mullins PA, Thuraisingham SI, Taylor G, Petch MC, Schofield PM. Effects of transcutaneous electrical nerve stimulation on coronary blood flow. Circulation 1994;89:694-702

3 De Landsheere C, Mannheimer C, Habets A, Guillaume $M$, Bourgeois I, Augustinsson $\mathrm{LE}$, et al. Effect of spinal cord stimulation on regional myocardial perfusion assessed by positron emission tomography. $A m \mathcal{f}$ Cardiol 1992;69:1143-9.

4 Kujacic V, Eliasson T, Mannheimer C, Jablonskiene D, Augustinsson LE, Emanuelsson H. Assessment of the influence of spinal cord stimulation on left influence of spinal cord stimulation on left
ventricular function in patients with severe ventricular function in patients with severe
angina pectoris: an echocardiographic study. angina pectoris: an echocardio

5 Hautvast RWM, de Jongste MJL, Staal MJ, Blanksma PK, Lie KI. Spinal cord stimulation in myocardial perfusion in patients with refractory angina pectoris as assessed by positron emission tomography. International Neuromodulation Society: Proceedings of the second international congress Gothenburg, 1994.

\section{Simon Dack}

SIR,-May I clarify an editorial adjustment made to the appreciation of Simon Dack (British Heart fournal, August 1994, page 104)? In the course of editing the manuscript an error crept in which I only saw in the published version. Once Dr Dack had retired from the Editorship of the Fournal of the American College of Cardiology, Dr Parmley enlisted him as the outside consultant editor for articles emanating from $\mathrm{Dr}$ Parmley's own institution, the University of California, San Francisco, and not, as appears, the Mount Sinai Hospital. I only take the trouble to point this out as the purpose was to maintain the highest possible standards of peer review, to which Dr Dack was devoted: the idea that Dr Parmley had was to continue to use his services so that there would be completely independent editorial assessment of contributions submitted to the fournal of the American College of Cardiology from the University of California, San Francisco.

D M KRIKLER

Past Editor British Heart fournal 